\title{
Energy Relations and Policy Making in Asia
}

A Brief Summary of the Book 


\section{About KAPSARC}

The King Abdullah Petroleum Studies and Research Center (KAPSARC) is a non-profit global institution dedicated to independent research into energy economics, policy, technology, and the environment across all types of energy. KAPSARC's mandate is to advance the understanding of energy challenges and opportunities facing the world today and tomorrow, through unbiased, independent, and high-caliber research for the benefit of society. KAPSARC is located in Riyadh, Saudi Arabia.

\section{Legal Notice}

(C) Copyright 2016 King Abdullah Petroleum Studies and Research Center (KAPSARC). No portion of this document may be reproduced or utilized without the proper attribution to KAPSARC. 


\section{Key Points}

rade between the economies of the Gulf Cooperation Council (GCC) and North East Asia (NEA) reached $\$ 471$ billion in 2013 , based almost entirely on oil and gas. The GCC sends 44 percent of its exports to NEA, which depends on the GCC region for a very high proportion of its oil imports. Trade relations are otherwise very limited: the GCC takes only 3 percent of NEA's exports.

GCC-NEA energy links beyond trade are limited. Restrictive upstream ownership laws have largely restricted GCC-NEA joint ventures to a handful of refining projects.

Current energy trade links are vulnerable to price shocks, distortion of distribution channels, and new sources of hydrocarbons. A possible route to continued trade and cooperation is through opening markets, joint oil stockpiling, technology exchange and a shared understanding of energy security risks.

The environmental agenda - i.e., renewable energy and improved energy efficiency - represents an opportunity. NEA enjoys great expertise in low-carbon technologies and could be a partner of choice for the GCC to adopt new technologies, freeing up reserves for export. Both sides have the opportunity for a broader trade relationship if barriers and bureaucracy can be reduced.

Enhanced communication and trust between the GCC and NEA economies is essential to guard against counterproductive responses to anticipated market dynamics, based on a fear of change and instability. 


\section{Summary}

E

nergy security is not a new topic for policymakers in NEA. The paradigm

usually adopted by both researchers and policymakers has been to view energy security as an asymmetric risk. Energy suppliers worry about security of demand; energy consumers worry about security of supply and often about diversity of supply. Our premise is that it is time to replace this paradigm with a new one. Energy security need not be about asymmetric risks: policymakers can, by adopting a broader view, use these energy relations to reinforce mutual interdependence between economies and reduce the risk asymmetries.
These ideas were discussed in a series of workshops held in the GCC and NEA throughout 2015. The result was a collection of papers from 16 different collaborating research institutions on a range of perspectives, with four main themes: the consequences of trade and connectivity; domestic policies; energy security and energy; and the environment. These collected papers are being published by Palgrave Macmillan in 2016, under the title Energy Relations and Policy Making in Asia.

As shown in Figure 1, in 2013 the countries of the GCC exported \$367 billion worth of goods, almost

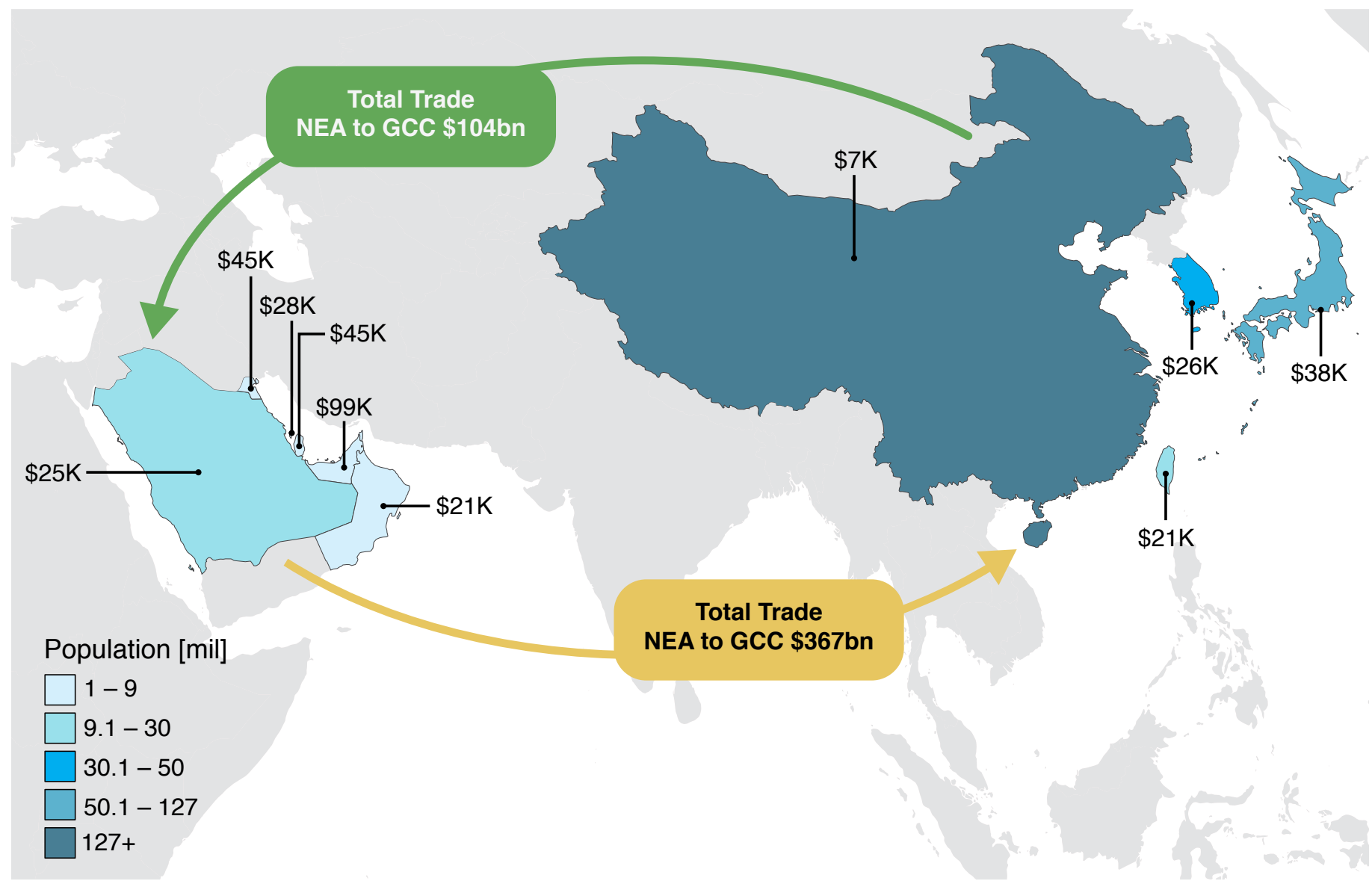

Figure 1. Total trade flows from NEA to GCC, and GCC to NEA, 2013.

Source: KAPSARC analysis. 
entirely hydrocarbon related, to NEA while imports from NEA totaled $\$ 104$ billion. To put these numbers in perspective, 44 percent of GCC exports flowed to NEA and 23 percent of GCC imports came from NEA. By contrast, 10 percent of NEA imports came from the GCC, a market which accounted for only 3 percent of NEA's exports. The picture of NEA dependence on the GCC changes markedly if the focus is centered on oil: Japan imports 74 percent of its oil from the GCC, South Korea 71 percent and China 35 percent.

Despite this trade, and the interdependence it might suggest, in other areas the energy relations are very limited. Restrictive upstream ownership laws in both the GCC and NEA have reduced joint ventures to a handful, mostly downstream in refining or through the liquefied natural gas (LNG) projects of Qatar Gas. The only upstream GCC-NEA joint venture is Kuwait's stake in China's Yacheng oil field.

The hydrocarbon trade between the GCC and NEA is also vulnerable to a trio of potential shocks: price volatility; the discovery and exploitation of new fuel sources, such as methane hydrates; and even new supply sources for conventional hydrocarbons. Any of these could shift the energy relationship between the two regions, suppressing economic growth and oil demand, or fundamentally altering the current supply and demand balance and associated trade flows. How the GCC responds to these vulnerabilities will be key to shaping future relationships.

For some years, NEA, and especially China, has been seen almost as a boundless market, soaking up oil and gas. However, demand growth is weakening, storage facilities are filled and NEA markets may no longer be able to absorb excess cargoes. Even in China, the gas supply situation may become much less tight by 2020 , once again presenting a challenge to GCC exporters. How countries in the GCC respond to this, to their own growing demand and even to within-region politics and rivalries will again shape the inter-regional relationships. By contrast, the development of oil stockpiles in NEA, and of energy cooperation within and between the regions, could do much to deepen and strengthen the relationships, even against the backdrop of shifting demand.

Despite forecasts by Japan's Institute of Energy Economics (IEEJ) that fossil fuels will continue to supply 80 percent of global energy needs until 2050, environmental concerns have raised the profile of low-carbon technologies, in the form of either renewable energy or improved energy efficiency. More importantly, the costs of renewables continue to fall, and forecasts suggest that solar and wind will be the fastest growing energy sources in the years to come. This is an area that seems perfect for building cooperation between the two regions. The GCC, with plentiful renewable energy resources, is suffering from growing energy demand and has struggled to improve its energy efficiency. In contrast, NEA economies have great expertise in renewable and energy efficient technologies, and can share lessons learnt in using policy to drive improvements in energy efficiency.

Taken together, the energy relations between the GCC and NEA are robust and, while there are vulnerabilities, there are also opportunities to offset them. Energy relations need not be merely transactional. In the 21st century, they can also be a way to improve mutual interdependence, to build trust and to lower risk. 


\section{Background to the Project}

C onventional analyses of international energy relations stress the asymmetric nature of the risks and costs of disruptions to energy flows. Energy suppliers - net exporters - are concerned about the cost of a buyer looking elsewhere. Energy consumers - net importers - are preoccupied with the costs associated with an interruption of supply. This perspective reflects the current transactional nature of energy relations and is clearly observed in the energy dynamics between countries in the GCC and the economies of NEA.

The Belt and Road Initiative of Chinese President Xi Jinping's government is seen by many as an attempt to reset the nature of the relationships China enjoys with other countries. Long regarded as the workshop of the world, China has enjoyed huge growth off the back of trade. But the country remains anxious, with a set of relationships that it views as insufficiently strong. The Belt and Road Initiative is perhaps an attempt to bolster these transactional trade relationships with infrastructural and investment links.

Despite the obvious importance of the energy trade to both the GCC and NEA, even here both sides seem anxious about the health of this relationship as it relates to energy trade. Amazingly, the often circulated China Daily map of the Belt and Road Initiative fails to show a node anywhere in the GCC (as shown in Figure 2). Both land and sea routes loop past the region.

\section{New Silk Roads | China is assembling new trade routes, binding other regions closer to it}

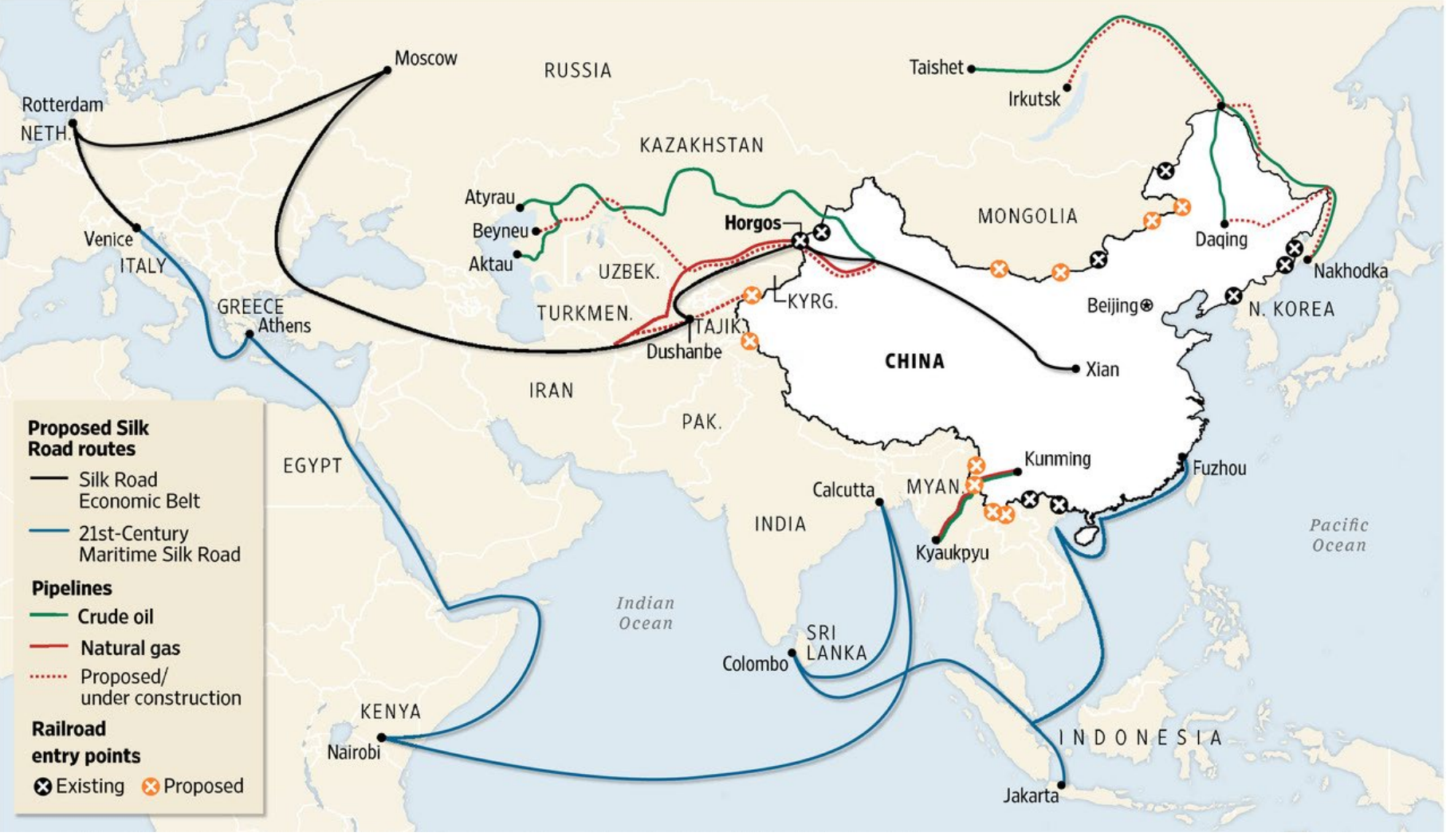

Figure 2. Original plans for the One Belt, One Road Initiative linked to roads, pipelines, and rail.

Source: China Daily. 
In conversations with both sides it became apparent that this was not by design, but rather through a lack of understanding. In KAPSARC's discussions with academics and policymakers in both the GCC and NEA, two things were constant: a lack of familiarity with the opposing region and a thirst for greater knowledge. This project was our response.

Through a series of workshops held in Hong Kong, Bahrain, Tokyo, Riyadh and Beijing in 2015, KAPSARC brought together experts from leading energy, strategic and economic policy think tanks to discuss how energy relations are forming in the 21st century. The result was the premise that energy relations in Asia in the 21st century should reinforce mutual interdependence.

As the economies of both the GCC and NEA have enlarged, there is under-recognized potential for a move away from narrow, transactional relations to broader, interdependent ones. Examining the dynamics of bilateral energy relations between countries in the GCC and NEA, we found four areas where these mutually interdependent relationships are being forged:

Trade and connectivity.

Domestic policies.

\section{Energy security.}

Energy and environment.

Each of the contributing scholars and experts brought their own perspectives to this extended dialogue, and each contributed a paper, which was collated in an edited volume entitled Energy Relations and Policy Making in Asia, published by Palgrave Macmillan. The 14 original essays were grouped across the four areas, which became the themed sections in the book.
1. Trade is at the heart of all energy relations, yet the underlying dynamics between the GCC and NEA are constantly changing. The essays in this section focus on the current energy trade in Asia, how it is vulnerable to potential shocks, how it is evolving in the face of changing supply and demand and how it can be made more stable though greater interdependence.

2. How countries trade and what they trade is often most affected by domestic policies, but this is insufficiently considered in conventional analysis of energy relations. The essays in this section consider how both policy driven and other changes in domestic energy sectors affect GCC-NEA gas dominated bilateral trading relationships.

3. Energy security is the 'typical' lens through which energy relations in Asia are examined. In the third section, this volume goes beyond the conventional energy security arguments and examines the role of stockpiles and seeks to understand the relevance of energy security fears for both the GCC and NEA.

4. Asia's energy relations in the 21st century increasingly focus on the interplay between energy and the environment. The fourth section includes essays that focus on how renewables and energy efficiency measures will affect the traditional oil-based relationships between East and West Asia.

Analytically rigorous but also policy relevant, the contributions incorporate historical approaches, qualitative policy analysis, empirical statistical analysis and modeling and simulation to support the arguments. 


\section{Existing GCC-NEA Relationships}

$\mathrm{T}$ The trade links between the GCC and NEA are massive and globally important, but also poorly diversified and perceived to be uniquely vulnerable to disruption.

In 2013, total trade between the two regions was over $\$ 470$ billion, with $\$ 367$ billion worth of trade flowing from the Gulf to NEA, but only $\$ 104$ billion going in the opposite direction. The enormous trade surplus accruing to the GCC had grown rapidly over the years up to 2014, but has since contracted due to falling hydrocarbon prices. These numbers mask a fragility based on three elements.

First, the trade base is exceptionally narrow. Virtually all of the GCC's NEA exports are hydrocarbon based and although NEA exports to the GCC are much more diversified - with electronics and automotive related goods the largest elements, but with many other types of goods as well - the GCC represents a tiny market for NEA: just 3 percent.

Second, this lack of export diversity makes the trade between the GCC and NEA extremely vulnerable to price shocks: there is not enough of a trade portfolio for price movements to average out. The fall in oil prices since 2015 has seen a substantial loss in revenue for the GCC.

Third, with over 50 percent of the GCC's oil exports flowing to NEA in 2013, the sensitivity to trade disruptions is acute. This is a sensitivity shared by NEA: Japan acquires 74 percent of its oil from the GCC, with 33 percent directly from Saudi Arabia; South Korea 71 percent (34 percent); and China 35 percent (19 percent).

Despite the obvious importance of the energy trade to both sides, there has been surprisingly little investment by NEA entities in the GCC's energy sector. The relationship has largely consisted only of trade.
An obvious reason for this limited cross investment has been the restrictive upstream ownership and investment laws across the GCC and also in China, the world's fourth largest oil producer after the U.S., Russia and Saudi Arabia. Perhaps the only major example is the 30 percent equity stake taken by Kuwait's Foreign Petroleum Exploration Company in China National Offshore Oil Company's (CNOOC) Yacheng Oil field. An obvious comparison is the much greater role of the IOCs in both regions.

Downstream, laws are markedly more relaxed, but even here engagement between the two sides has been limited compared with that seen elsewhere in the world. The Oman Oil Company (OOC) has a 30 percent stake in a South Korean power generation company, GS Electric Power and Services. OOC also owns 30 percent in China's Qingdao Lidong aromatics project and 30 percent in the port services venture Qingdao Lixing Logistics.

Saudi Aramco has a few refining projects with China, Korea and Japan. The company has joint ventures with Sinopec in both Saudi Arabia (Yasref) and China (Fujian Refining and Petrochemical Company). Japan is involved in the Petro Rabigh refining and petrochemical complex and also partners with Saudi Aramco in a Japan based crude oil storage lease agreement and in the Showa Shell Sekiyua refining and service station company.

By far the most outward looking of the GCC countries is Qatar which, through Qatar Petroleum and its subsidiary Qatar Gas, has been particularly active in cooperation with Japan and South Korea.

This list of GCC-NEA joint ventures underscores the lack of cooperation between the two sides. Widening the scope from energy to trade reveals further missed opportunities. As both an export and import market, the GCC represents a tiny 
fraction of total imports and exports for all four NEA economies. The GCC markets have experienced rapid growth over the last decade, but this has failed to translate into the increased imports from NEA that could be expected. For example, from nearly 2,000 tariff items identified as enjoying demand growth in the GCC, Taiwan currently exports to the
GCC only 51. A further 110, including fabrics, glass, metal and machine parts, are exported worldwide, but not to the GCC. Even with such clearly identified opportunities for further trade, growth is slow.

Onerous bureaucratic and inspection procedures in the Gulf have been cited by entrepreneurs for raising the costs of business exorbitantly. 


\section{Shocks and Vulnerabilities}

$\mathrm{T}$ The most obvious vulnerability to which the energy trade is exposed is price shocks.

There have been oil price spikes for as long as there has been a modern oil industry: the Iranian revolution; the Iraqi invasion of Kuwait; and the mid2000s; to identify just three events. Regardless of absolute price levels, volatility has been associated with recessions in several studies. Price spikes have tended to raise inflation and unemployment while lowering output; price volatility has dampened international trade.

While it may appear obvious that the value of the oil trade is positively correlated with oil price, China's export led development, and the commodity supercycle that it encouraged, over the last 20 years has also meant a positive correlation between oil price and non-oil trade between China and the GCC. By contrast, oil price volatility has a negative correlation with trade. Again, over the past two decades, a 1 percent drop in oil price volatility has led to a 0.65 percent increase in trade between China and the GCC: oil trade up by 0.83 percent, non-oil trade up by 0.42 percent.

Shocks to supply and demand have different consequences for China-GCC trade. When oil prices rose as a consequence of global economic growth, China-GCC bilateral trade also increased. Oil supply shocks, on the other hand, seemed to have limited effect on China-GCC trade, perhaps because of the political favor and protection shown towards the relationship.

What becomes apparent is that the strength of the relationship can help inject stability into the trade relationship, even when the fundamentals are volatile. Boosting oil volumes traded and increasing overall trade between China and the GCC can therefore strengthen the trade relationship by boosting its importance and increasing the likelihood that policymakers will find ways to protect the trade flows. In this sense, the long held Chinese belief in diversification could actually be detrimental to the stability of trade links with the GCC by reducing their importance. Successfully concluding the ChinaGCC Free Trade Agreement could therefore be one way of boosting trade and stability.

Price volatility is not the only shock to which GCCNEA energy relations are vulnerable. Supply shocks have the potential to be of far greater consequence. The U.S. shale revolution has drastically redrawn energy relations in two ways. First, NEA has become increasingly important as the remaining growth region for GCC energy exporters, even as NEA demand growth has slowed. Second, the increase in production from the U.S., coupled with slowing demand, has helped produce the current sustained fall in prices and the growing stress that has been placed on GCC budgets.

This story of U.S. unconventional oil, shifting supply and demand trading relationships and undermining the oil price, could be repeated through two different vulnerabilities. First, the emergence of new sources of conventional oil supply. The GCC is not the only region to pivot east in its oil sales: Russia, too, has been reorienting at least part of its oil flows to Asia in the face of weak demand from its traditional European export markets. Long-term contracts between Russia and China will see an expansion in East Siberia-Pacific Ocean (ESPO) exports, though it is currently unlikely that there will be further capacity upgrades beyond those already in process.

The GCC has already lost market share in Asia. West Africa, Latin America and the Former Soviet Union have now all emerged as major suppliers to that region. In 2008, the Middle East provided 78 percent of oil imported by NEA, but in 2014 this was down to 66 percent. It should be noted that, in absolute terms, 
Middle East exports to Asia have still increased over this period, from almost $14 \mathrm{MMbbl} / \mathrm{d}$ to over 15 MMbbl/d. Specifically for GCC to NEA, exports rose from 5.6 MMbbl/d in 2003 to $7.1 \mathrm{MMbbl} / \mathrm{d}$ in 2013.

Despite these past increases, the GCC may well face growing competition. It is expected that Asia's share of Russian oil exports will grow from 6 percent in 2015 to $20-25$ percent by 2030 . Much will flow to NEA, where Russia enjoys a significant geographical advantage over the GCC. Transport links to/from Russia are much shorter and avoid contentious choke points that worry NEA energy strategists, such as the Malacca Straits.

Significant new technological discoveries that may impact the relationship are hard to predict, but can certainly introduce unforeseen wrinkles into GCCNEA energy trade. For example, while methane hydrates are often deemed unlikely by analysts, they may present a potential black swan event that could once again change global energy flows. Methane hydrates are ice-encased methane; global reserves of methane hydrates are thought to exceed all other hydrocarbon reserves. Their potential is huge and their abundance in NEA - in excess of 12 trillion cubic meters, with 6 tcm in Japan - could lead to traditionally energy poor countries such as Japan becoming gas independent.
Despite their potential, successful commercial exploitation of methane hydrates remains some way off. Japan and Korea are probably the closest to the necessary technological breakthrough, but even here commercial production is not expected before the mid to late 2020s, with full development unlikely soon. Low oil and gas prices may reduce the competitiveness of methane hydrates and further extend this time line, and in the competition with other emerging technologies some analysts cast doubt on their ever becoming a commercial reality. On the other hand, few accurately predicted the growth of shale gas in the U.S.; methane hydrates may yet repeat this story.

What can the GCC do in the face of new competition? Despite the ardent desire of NEA policymakers for direct price negotiation, this is unlikely to take place given the current market structure. The market determines the spot price for benchmark crudes such as Brent, West Texas Intermediate or Dubai. Formula prices then define official selling prices for contracts at a discount or a premium to the benchmark. Individual suppliers can set discounts to the benchmark, but these are then applicable to all term contracts, not specific ones. There is greater negotiation potential with non-price incentives, and GCC suppliers have been known to offer reduced shipping rates or enhanced credit terms. 


\section{Energy Security: Asymmetric Fears}

tructural changes in NEA energy demand, particularly for gas, could increasingly cause uncertainty about GCC security of demand. Gas demand growth in China is slowing. Its gas consumption rose from $23.5 \mathrm{bcm}$ in 2000 to 185.5 bcm in 2014 and NEA accounted for more than 50 percent of the growth in world oil consumption since 2008. But from that period of double digit growth, in the first half of 2015 year-on-year gas demand slowed to 3.3 percent. Despite being the world's sixth-largest gas producer, Chinese domestic gas production has lagged behind consumption and imports have grown rapidly, reaching $58.4 \mathrm{bcm}$, or 31.5 percent of total, by 2014 . Of this, $31.3 \mathrm{bcm}$ were through pipelines, the first of which opened in 2009, and $27.1 \mathrm{bcm}$ was in the form of LNG, which started arriving into China in 2006. Qatar, the world's largest LNG exporter, provided almost 35 percent of China's LNG.

It is expected that Chinese gas demand will rise to 312 bcm by 2020 , though low and high growth scenarios give a range of 290 to $350 \mathrm{bcm}$. This slower than expected growth in gas demand has knock-on effects for China's gas imports. Domestic production is currently declining year-on-year and China's energy industry has struggled to open up new reserves. Shale gas and coal bed methane have also been developed more slowly than originally targeted. In total, the China Petroleum and Chemical Industry Federation is now predicting total domestic gas production to be around $224 \mathrm{bcm}$ in 2020, shy of the National Energy Administration's 2020 target of $245 \mathrm{bcm}$.

The shortfall will be covered via imports, both pipeline gas and LNG. China's policymakers have targeted new pipelines as a key part of their energy security policy. Three major new pipelines are scheduled to bring on $135 \mathrm{bcm}$ of capacity by 2020 . The Central Asian Natural Gas Pipeline, which runs south to northeast through Turkmenistan, linking up with the West-East Pipeline, was completed along with the Sino-Burmese pipeline in 2014; a fourth channel in the Central Asian pipeline is expected by 2016; the Sino-Russian pipeline running to the northeast of China is expected to be completed by 2018. Scheduling uncertainties lead some analysts to predict only half the nameplate capacity will be filled by 2020. The rest will come from LNG, but even forecast imports are expected to be well short of nameplate regasification capacity: 51 million metric tons as against 80 million metric tons.

China's policymakers, fearful of failing to find enough gas for the country's impressive economic growth, could well find themselves in 2020 having over-built import capacity and over-estimated demand. With greater capacity than necessary to manage gas imports, China may find itself in the position to choose the cheapest among competing gas supplies - so long as cheaper options are also secure options. This may well be bad news for Qatari LNG. While Qatar was the largest supplier of LNG to China in 2014, these imports fell by over 48 percent in the first half of 2015. Qatari LNG, contracted at times of high oil prices, is the most expensive gas currently flowing into China.

Yet, while one set of energy security dynamics in China has led to the possible over-estimation of domestic demand and over-construction of import infrastructure, a competing set of energy security dynamics may actually be raising the amount of gas available for export to China.

Qatar has ambitious plans to produce 2 percent of its electricity from solar power by 2020 , and then to expand that to 20 percent by 2024. Given the country's current almost total reliance on gas for electricity generation, such renewable targets will free up gas to help meet either growing domestic consumption or increased export. 
North East Asia is Qatar's single most important market: the region accounted for 41 percent of Qatar's LNG exports in 2013. In absolute terms, both Korea and Japan buy more Qatari gas than China, but China was, between 2009 and 2013, by far the fastest growing market. Between those years, the gas trade between Qatar and China had a CAGR of 76.8 percent, between Qatar and Japan a CAGR of 15.3 percent and with Korea, 14.3 percent. Overall trade between China and Qatar has also been growing, while Qatari trade with both Japan and Korea has fallen since 2009. China has therefore come to be seen as the future market for Qatari gas.

Yet Qatari LNG exports to NEA face growing competition. Unconventional gas exports from the U.S. are already beginning to affect the competitive landscape but, more importantly, China's shift from a tight gas market to a possible oversupplied gas market by 2020 , will likely see high priced Qatari gas continue to lose ground. In addition, Australia is set to emerge as the world's largest LNG exporter post 2020, while Africa and Russia are also set to increase their exports. While there are clear environmental benefits to Qatar's pursuing an expansion of solar power in its electricity generation capacity, and while domestic price reform can certainly help Qatar optimize its own gas consumption - both of which will maximize the amount of gas available for export - the NEA market will be increasingly sensitive to price as the supply balance shifts in its favor.

Its position as the most expensive gas supplier to NEA in an environment of increasing competition poses a problem for Qatar, especially as it has positioned itself within the GCC as an exporter of LNG, prioritizing market based commercial relationships with distant energy consumers over political - i.e., selling gas at a substantial discount to the market - relationships with geographic neighbors. The fall in global energy prices since 2014, combined with the slowing growth of energy demand across Asia, has increased Qatar's vulnerability to NEA, at the same time as the country's dependence on the region has grown. When gas demand in Europe fell by 20 percent between 2010 and 2014, Asia took up the slack. Indeed, Qatar's relationship with NEA rests upon more than just the sale of LNG: of all the GCC countries, Qatar is most entwined with Japan through joint ventures and investments in its various gas projects.

Yet as Qatar built up its commercial links with growth energy markets such as NEA, it did so at the expense of local relationships. This is not because Qatar's GCC neighbors do not want gas: they do. Apart from Qatar, the five remaining GCC members all experience gas shortages. Discussions to develop a strong intra-GCC network of gas supplies have met with little success. The Dolphin gas pipeline, conceived in 1999 to produce, process and transport gas from Qatar's North Field to UAE and Oman, is one example of joint infrastructure, and it is as much an example of failure as one of success.

Shortcomings in legal, governance and institutional frameworks have stymied GCC integration, but so, too, has a lack of political will. Qatar, especially, felt isolated in the GCC after the regime change in 1995. Long before that, in the 1980s, Qatar had sought support for a pipeline network to deliver gas to the rest of the GCC. In 1990, Saudi Arabia pulled out and then refused to grant transit rights from Qatar to Kuwait. But at the core of that dispute was a disagreement over price, which was based on the unreformed - and extremely low - domestic gas prices GCC countries charge their populations. Dubai, for instance, was unwilling to pay Qatar more than \$1/MMBtu. Saudi Arabia's domestic gas price is just $\$ 0.75 / \mathrm{MMBtu}$. When the Dolphin 
project to supply UAE with Qatari gas came on stream in 2007, it was below scope: the pipeline's nameplate capacity is 3.2 bcf/day, but current compression facilities and contracts allow for only $2.2 \mathrm{bcf} /$ day. Dolphin has certainly been a success by the yardstick of GCC cooperation, but the Qatari government has seen little incentive to prioritize the sale of gas to its neighbors when it is at such a discount to prevailing international prices, even if it is willing to at least notionally subscribe to the idea of regional cooperation and supply. The unreformed - i.e., extremely low - gas price in GCC countries continues to undermine the region's gas security: consumption is high and there is little incentive for Qatar to supply gas when it can secure higher prices outside the GCC. Recent moves to reform prices in the Gulf States are unlikely to change this situation in the short term.

The energy security concerns of Qatar and other GCC countries are, at the core, not dissimilar from those facing NEA. Countries such as China are concerned about dependence on any single supplier, just as the GCC suppliers are concerned about over dependence on a single buyer. Related to this is an anxiety over political stability and how stability, or lack of it, affects the flow of oil. Additionally, governments worry about availability - what percentage of a supplier's volume does a single buyer take - affordability and price volatility.

The exact nature of energy security risks varies from country-pair to country-pair and from year to year. But stability has long been perceived by NEA as the most important element. Periods of political instability and political violence have historically been associated with lower oil exports, and GCC oil exports are especially sensitive to transnational episodes of violence and instability. Yet, while this is true, economic factors - non-political events - have far greater power when it comes to explaining the fluctuations in oil flows.
For policymakers concerned with stability, China began developing its Strategic Petroleum Reserve, taking advantage of current low prices to build up stockpiles at lower cost. This is intended to be a three phase process, with a final capacity of roughly 500-700 million barrels by 2023. In doing this, it is adopting a policy similar to that of the rest of NEA. Japan currently has an estimated capacity of 900 million barrels: 542 million under the direct control of the Ministry for Economy, Trade and Industry and 316 million under the control of an agent company, Japan Oil. In turn, Korea has total storage of 291 million barrels, 146 million of which are under the control of the national oil company. Stockpiling has long been regarded as an effective way to reduce risks related to oil supply; it is, however, expensive.

Perhaps one way to reduce the costs of stockpiling is through joint stockpiling, a policy that can also help to align the energy security interests of exporters and importers. For importers, energy stockpiles provide easy access in times of relative shortage; the exporter benefits from having its oil close to the point of consumption, allowing instant access with low transport risk. If multiple parties are involved, the costs of facility maintenance can also be shared, reducing the overall costs. Of course, for a system designed to provide emergency cover for an economy's energy requirements, joint stockpiles can involve difficulties over real control and ownership. If more than one energy consumer is relying on the storage facilities, joint ownership and access contracts may become irrelevant during a breakdown in international relations: location will give ultimate control to the host nation, regardless of contractual clauses.

Joint stockpiling projects are found in Japan, where Japan and Saudi Aramco have a 6.3 million barrel facility. There is a further 6.3 million barrels of joint stockpiling with the Abu Dhabi National Oil Company (ADNOC). Korea also has a 6 million 
barrel joint stockpiling facility with ADNOC. A 2007 strategic alliance between Korea and Japan failed to gain traction as trust and relations between the two countries have weakened, even against a background of historically fraught relations.

Improving communications is probably the single most important element in ensuring stable relations, particularly as the underlying structure of the energy trade relationship is evolving. Transparency can improve trust and reduce governments' perceived need to go back to the old paradigm of costly unilateral reactions in response to perceived risk asymmetries. Communication can remind all involved that individual governments, economies and societies are not islands, but interconnected in countless ways. This is as true for maintaining political relations as it is for reducing the effects of unexpected economic shocks. Communication is of paramount importance for joint stockpiling projects, especially if multiple countries have access rights. As countries in both the GCC and NEA have moved to protect themselves from their perceived asymmetric energy security risks, good communications have proved to be perhaps the most cost-effective way to ensure the stability that all parties are seeking. 


\section{Responding to the Environment}

A Ithough the relationship between the GCC and NEA has traditionally been framed in terms of hydrocarbons, both renewable energy and energy efficient technologies are opening up new opportunities.

Currently, low carbon energy provides just 10.5 percent of NEA's total energy consumption, against a woeful less than 0.004 percent for the GCC. Countries in both regions have targets to expand low carbon energy generation and are richly endowed with low carbon energy resources, solar and wind being the prime examples. Bahrain seeks to have 5 percent renewable energy use by 2020; Kuwait and Oman are targeting 10 percent renewable electricity generation by the same year; Qatar has ambitious plans for 20 percent solar power by 2024, while Saudi Arabia has called for 10 percent of electricity to come from non-hydrocarbon sources by 2030. Dubai wants to have 5 percent of final energy consumption from renewables by 2030 .

Similar targets are found in NEA. China plans to increase non-fossil energy to 15 percent of total primary energy supply by 2020 , Japan is planning to more than double its current renewable capacity by 2020, to reach almost 86 GW, and South Korea is targeting 11 percent by 2035 .

Furthering their own use of renewable energy, NEA economies can also reduce their oil and gas demand, again reorienting the traditional, hydrocarbon dominated trade links. But they can do more than that. As world leaders in these technologies, NEA economies have the ability to become energy exporters to the GCC. China can help export and install wind technology; Japan could leverage its well established photovoltaic electricity generation technologies.
This cooperation has already begun. The UAE is partnering with South Korea to build four nuclear reactors and Saudi Arabia has signed memoranda of understanding (MoUs) with China, in August 2014, and South Korea, in March 2015, to promote nuclear and renewable technology cooperation. Japan has been active in the GCC solar market since the 1980s, providing equipment, collaborative research and financial support. The greatest barrier to increased GCC-NEA cooperation in renewable energy is the price environment in the GCC, where oil and gas prices are extremely low. This, coupled with traditionally conservative targets for renewables, has slowed development of wind and solar markets and limited NEA engagement.

Combined with renewables targets, governments are increasingly adopting greenhouse gas (GHG) emission reduction targets. Japan, for example, is seeking a 26 percent reduction in GHG emissions by 2030 against a 2013 baseline. At least some of this reduction will be driven by efficiency savings and by behavior changes that ultimately lower energy consumption. These are areas where sharing best practice between countries can lead to rapid, cost effective changes being adopted across regions. The NEA has a wealth of energy saving knowledge that can be readily shared with countries in the GCC. But the sharing of best practice also requires a nuanced approach to the designing of energy conservation policies that acknowledge the global nature of energy use and emissions. Purely domestic actions to reduce GHG emissions can actually lead to an increase in global emissions, as energy intensive industries are pushed out to developing economies with more lax environmental standards and less efficient industrial processes. Marrying best practice with efficient technology and accurately measuring energy and emissions is an important step toward a true reduction in energy use and true collaboration between the regions. 
Countries that look only to their direct energy balance, ignoring the energy and emissions embodied in the goods and services they import from elsewhere, have failed to recognize a key part of the puzzle. Although Saudi Arabia and the rest of the GCC are major energy exporters, they are also importers of embodied energy. Indeed, the UAE actually imports more embodied energy than it uses directly, as does Japan. The energy embodied in an economy's exports can also make up a substantial component of the country's total energy use. The embodied energy exports of China, Japan and South Korea make up 39 percent, 28 percent and 109 percent, respectively, of their energy for domestic consumption. South Korea's high figure comes at least in part from its re-export of petroleum products.

Adopting an embodied energy accounting system does not render energy and emission reduction targets unnecessary, but it does boost communication. In addition, there can be improved understanding of how economies are interlinked through their energy relations, and of how opportunities for enhanced relationships that look beyond traditional hydrocarbon sales can benefit the energy security, and economic and environmental prosperity of all involved. 


\section{Conclusion}

his project took at least part of its cue from China's Belt and Road Initiative - but if that policy seeks to build infrastructure to physically bind economies closer together, this project takes a broader view of the possible relationship set available to economies in both the GCC and NEA. Physical infrastructure projects may deliver enhanced benefits and may boost connectivity and interdependence, but they are not the only route.

Clear focus by policymakers on some additional factors could complement efforts to solidify ties through the development of infrastructure:

Understanding of new trade opportunities.

Enhanced awareness of vulnerabilities masked by current trading relations.

Focus on the limits to current cross investments.

Knowledge sharing so that the GCC can leverage NEA expertise in renewable energy.

Understanding how decisions taken in one country can both create opportunities for another country and yet also confound the expectations of a third, can again reduce the perception that each country is alone, and each subject to asymmetric energy security risks.

Understanding what are the real components of energy security can be aided by understanding that while political stability is certainly important to maintain energy flows and economic growth, economic stability is even more central.

Understanding how the new environment provides opportunities for both sides to work together to share best practice and reduce the costs of energy for all sides can also help boost trust, aid understanding and, ultimately, lower the perception of asymmetric risks.

Most important, policymakers can re-evaluate fears that bilateral relations among NEA-GCC are at risk through improved trust and communication. Energy will flow. Commerce will continue. But the opportunity to substantially improve relationships rests upon improved understanding, improved communication and enhanced trust. It is here that this project seeks to make its real contribution. 


\section{Appendix A: List of Chapters}

Book Editor: Leo Lester (KAPSARC)

Introduction

Authors: Duc Huynh (Saudi Aramco),

Yugo Nakamura (Aramco Asia Japan)

\section{Part 1: Trade Patterns and their Consequences for Connectivity}

Effects of Oil Price Volatility on Bilateral Trade between China and the GCC w

Authors: Zhao Xaiowei, Li Taoya and Zhai Dayu (State Information Center)

Potential Impact of Methane Hydrate Development on GCC and NEA Energy Trade

Authors: Ahmed Kiani, Toufic Mezher, Steven Griffiths and Sameh El Khatib (MASDAR)

GCC-NEA Oil Trade: Competition in Asian Oil Markets and the Russian 'Pivot' East

Authors: Shahad Al-Arenan, Nader AlKathiri, Yazeed Alrashed, Tilak Doshi, Ziyad Alfawzan, Sammy Six, Vitaly Yermakov (KAPSARC)

Market and Hierarchical Interactions between East and West Asian Oil Sectors: Theory and Practice

Author: Omar Al-Ubaydli (Bahrain Center for Strategic, International and Energy Studies)

From GCC-Asian Energy-Oriented Trade to Comprehensive Trade and Investment Links: A Case Study of Taiwan

Authors: Yeh Chang-Chen (CIER), Kuo Po-Yao (CTCI Foundation), Jheng Ruei-He (CIER), Chen Chien-Chou (CIER), Liu Yu-Lin (CIER) and Liang Chi-Yuan (CIER)

\section{Part 2: Domestic Policies and their Consequences for Connectivity}

Changes in Chinese Natural Gas Demand and Their Potential Impacts on the Relationship Between China and the GCC Countries

Authors: Zhu Hanxiong, Pan Kexi and Chang Zheng (Energy Research Center of Fudan University)

Impacts of PV Adoption in Qatar on Natural Gas Exports to Northeast Asia and Ensuing Environmental Benefits

Authors: Antonio Sanfilippo and Larry Pederson (Qatar Environment \& Energy Research Institute)

The Dynamics of Energy Geopolitics in the Gulf and Qatar's Foreign Relations with East Asia

Authors: Remi Piet and Steven Wright (Gulf Studies Center, Qatar University)

\section{Part 3: Energy Security and its Consequences for Connectivity}

Evaluating the Impact of Oil Exports in GCC Countries on China's Oil Security

Authors: Ji Qiang (Center for Energy \&

Environmental Policy Research, Institute of Policy and Management, Chinese Academy of Sciences) and Fan Ying (School of Economics \& Management, Beihang University)

Assessing the Impact of Political Disruptions on Crude Oil Trade

Authors: Kenneth White, Brian Efird and Sadeem Alhosain (KAPSARC) 
Commercial Stockpiling: An Alternative for Joint Stockpiling of Oil in North East Asia

Author: Sangyoon Shin (Korea Energy Economics Institute)

\section{Part 4: The Environment and its Consequences for Connectivity}

Energy Embodiments of the GCC and NEA

Countries

Authors: Chen Zhanming and Li Tianyi (National Academy of Development and Strategy, Renmin University of China)
Analysis of Cooperation Potential on LowCarbon Energy between GCC and NEA

Author: Zhang Tingting (International Energy Research Center; School of Mechanical Engineering, Shanghai Jiao Tong University)

An Era of Collaboration to Promote Energy Efficiency

Authors: Yukari Yamashita and Rejean Casaubon (Institute of Energy Economics, Japan) 


\section{Appendix B: List of Contributing Institutions}

The Bahrain Center for Strategic, International and Energy Studies (DERASAT) is a think tank in the Kingdom of Bahrain dedicated to encouraging the use of research and dialogue to inform policymakers about key strategic and energy issues pertaining to the Arabian Gulf. It places a strong emphasis on developing Bahraini and Gulf research talent in an effort to ensure that Gulf policymakers have access to professional and impartial analysis on current affairs.

\section{The Center for Energy and Environmental Policy} Research (CEEP) is a joint research center of the Institute of Policy and Management, Chinese Academy of Sciences and the Economics and Technology Research Institute, CNPC. Addressing the solutions to national energy and environmental issues, CEEP conducts scientific research in the area of energy and the environment, promoting the development and application of energy economics, policy and management science. CEEP aims to provide energy scenario forecasting, energy system analysis and policy analysis for government and enterprises. CEEP provides decision support to both domestic and overseas development strategies for China's oil companies.

\section{Chung-Hua Institution for Economic Research} (CIER) has been serving as a policy think tank for the Taiwan government by making important recommendations, for which it has gradually gained prestige and recognition. The CIER engages in research with an emphasis on professional knowledge, innovative thinking and a concern for society, while maintaining an unbiased and objective stance in terms of providing sincere and constructive recommendations. By serving as a platform for exchange among academia, government and industry, CIER will continue to serve the need to promote the sustainable development of Taiwan's economy.
CTCI Foundation, a prestigious institute in Taiwan, was established in 1959 and has played a critical role in various Taiwan economic development projects. CTCI Foundation focuses on its ultimate goals - technological innovation, community wellbeing and economic development - and has implemented a think tank dedicated to energy, environment, and economic development on the whole. It has assisted the government to formulate a variety of policies and strategies pertinent to energy, environment protection and industry development. It has also sponsored a series of seminars, scholarships, and academic programs to identify talented professionals, thereby boosting research and development in Taiwan.

Fudan University is a leading institution in China. The Energy Research Center of Fudan University has competence in economics, energy policies and environmental and social efficiency research in China.

\section{The Gulf Studies Center at Qatar University} has as its prime objective the provision of a Qatarbased research center of international excellence for multidisciplinary academic research, stimulating and advancing education and research on a broad range of political, economic, social, environmental, and security issues and other matters relating to the Gulf region. The Gulf Studies Center aims to foster thoughtful dialogue among students, scholars and practitioners of Gulf affairs and to facilitate the free flow of ideas and knowledge through publication and dissemination of related information. It also seeks to provide a forum for scholarship and academic research and promote scholarly interest in the region among researchers within Qatar and beyond.

\section{The Institute of Energy Economics, Japan (IEEJ)} has been conducting specialized research activities in the areas of environment and energy economics for 
50 years. By adopting a neutral and scientific stance, the Institute carries out comprehensive studies and provides timely reports and analyses market developments, leading to policy recommendations regarding the challenges facing the world in general, in research fields such as energy and environmental issues, as well as geopolitical and economic analysis. IEEJ also holds and organizes domestic and international conferences and seminars. Through these activities IEEJ intends to serve as a world leading think tank, located in Japan, representing the interests of the global community within a world in constant evolution.

\section{The International Energy Research Center} (IERC) is an energy research institution, co-founded by both China Energy Fund Committee and Shanghai Jiao Tong University. To serve as a public energy diplomatic platform, the IERC is devoted to conducting research on critical international energy issues and providing suggestions and recommendations for national energy strategy and policy decision-makers. Recent research focuses include natural gas cooperation in Asia, One Belt and One Road and China's energy security, and haze issue.

\section{The King Abdullah Petroleum Studies and Research Center (KAPSARC) is a non-profit} global institution dedicated to independent research into energy economics, policy, technology, and the environment across all types of energy. KAPSARC's mandate is to advance the understanding of energy challenges and opportunities facing the world today and tomorrow, through unbiased, independent, and high-caliber research for the benefit of society. KAPSARC is located in Riyadh, Saudi Arabia.

\section{Korea Energy Economics Institute (KEEI) is a} government-affiliated research institute focusing on policy in energy, natural resources and climate change. Its performance and capabilities have enabled KEEI to be regarded as the primary institute of Korea in its research areas since its establishment in 1986.

\section{Masdar Institute of Science and Technology is} the world's first graduate-level university dedicated to providing real-world solutions to issues of sustainability. The Institute's ability to do this is critically dependent on a university culture that emphasizes research and development excellence, technology innovation and entrepreneurship. Nurturing this culture is the focus of its crossdisciplinary collaboration and its emphasis on both fundamental and applied research. By leveraging its distinctive strategic advantages, Masdar Institute provides its students with the technical knowledge and systems perspective critical to innovation and thought leadership. The Institute's goal is to become a world-class research-driven graduatelevel university, focusing on advanced energy and sustainable technologies. Located in the Masdar City in Abu Dhabi, the capital of the United Arab Emirates, Masdar Institute aims to support Abu Dhabi's economic diversification by nurturing highly-skilled human and intellectual capital and partnering with industry leaders. This will help the Emirates in its transformation to a knowledgebased economy and enhance its position as a leader in global energy. The Institute, which was created in collaboration with the Massachusetts Institute of Technology, integrates theory and practice to incubate a culture of innovation and entrepreneurship, working to develop the critical thinkers and leaders of tomorrow.

\section{The Qatar Environment and Energy Research} Institute (QEERI) is a mission-driven national research institute member of Qatar Foundation for Education, Science and Community Development operating under the umbrella of Hamad Bin Khalifa University. QEERI was established in 2011 with the mandate of leading the national Energy and Water 
Security Grand Challenges, aligned with Qatar's National Vision 2030 strategy. The Institute has four research tracks on the Energy Security Grand Challenge: solar photovoltaics; energy storage; grid integration; and energy efficiency. All of them support Qatar to achieve the deployment of largescale solar energy and reduce the risk of instability to the grid. More details about QEERI can be found at www.qeeri.org.qa.

Renmin University of China is a research-oriented comprehensive university focusing on humanities and social sciences. It is directly under the Ministry of Education of China and is jointly financed and supported by China's Ministry of Education and the Beijing municipal government. It can be traced back to Shanbei Public School, founded in 1937. It was the first modern university founded by the People's Republic of China.

Saudi Aramco is the state-owned oil company of the Kingdom of Saudi Arabia and a fully integrated, global petroleum and chemicals enterprise.
State Information Center (SIC) serves as a think tank under the National Development and Reform Commission (NDRC), China's top economic planner. One of its major functions is to provide decision-making support to the NDRC and other central agencies on issues including policy design, justification and simulation. The One Belt and One Road (OBOR) initiative has been given high priority in China's foreign affairs strategy in the 13th FiveYear Plan period (2016-20), a key time for China to fulfill its pledge of building a well-off society.

\section{The School of Economics and Management at} Beihang University, one of the first economics and management schools in China, has achieved remarkable accomplishments and is highly successful in discipline construction, research, education and public service. The school aims to enhance its research innovation ability through cutting-edge research, seizing the strategic opportunities in making China an innovative nation and strengthening the national defence industry. 


\section{Appendix C: List of Contributing Authors}

Ziyad Alfawzan is a research analyst at KAPSARC focusing on oil markets. His current research interests include understanding oil price mechanisms and its implications on realized revenues for National Oil Companies (NOCs). He holds a BSc in Industrial Engineering from King Saud University, Riyadh, Saudi Arabia.

Sadeem Alhosain is a senior research analyst focusing on energy and demographic changes, energy information management and energy politics. She holds an MS in E-Business Systems from City University London.

Nader AlKathiri is a research associate at KAPSARC. His current work focuses on understanding inter-regional price differentials of crude oil through spatial modeling. He recently co-developed the KAPSARC Global Oil Trade Model (GOTM), a spatial simulation model of the crude oil market. Nader holds a BSc in Operations Research from King Saud University, and an MS in Applied Mathematics and Computational Science from KAUST.

Shahad Al-Arenan is a research analyst at KAPSARC. She holds a BSc in Electrical and Computer Engineering from Effat University.

Réjean Casaubon is a councillor for The Institute of Energy Economics Japan (IEEJ), advising the chairman on strategies to increase IEEJ's visibility and think tank capacity on energy. Before joining the Institute, three years ago, he served as a civil servant (economist) for the Department of Natural Resources and the Ministry of Environment for the Government of Canada. Prior to his retirement, he managed a modeling team providing advice based on analyses of energy and climate change policies (carbon dioxide). Over the years, he has acquired a considerable knowledge of the oil, natural gas, coal and electricity markets, including associated greenhouse gas emissions.

Yeh Chang-Chen is an assistant research fellow at the WTO and RTA Center, CIER, Taiwan. His research interests include political economy, comparative political economy, international political economy, politics of developing areas, political and economic affairs in Asia-Pacific and Latin America region, international relations, media and politics, and trade and environment. Yeh holds a PhD.

Liang Chi-Yuan is a well-known energy economist domestically and internationally. $\mathrm{He}$ is the chairman of the Chung-Hua Institution for Economic Research (CIER), chair professor of the National Central University, supervisor of the Central Bank and managing director of Chinese Petroleum Corporation. He has also worked as research fellow of the Institute of Economics in Academia Sinica, senior adviser of the National Security Council and minister without portfolio, Executive Yuan. His research interests focus on energy economics, environmental economics, economic modeling and forecast, industrial economics and productivity analysis

Chen Chien-Chou is a research assistant at the Taiwan WTO and RTA Center, Chung-hua Institution for Economic Research (CIER). His research interests focus on issues of trade and environment, energy efficiency policies and security studies.

Zhai Dayu is an assistant analyst at the State Information Center of China. He holds a Bachelor of Public Policy from Peking University, China, and an MSc in International Political Economy from the University of Edinburgh, UK. His main focus area is international political economy, trade and regional integration. 
Tilak K. Doshi is a former senior research fellow at KAPSARC. He completed his PhD in Economics at the University of Hawaii under an East-West Center scholarship. His focus is on oil and gas markets and he has worked in a number of international oil companies in marketing and corporate planning functions. Tilak has authored two books and several articles on energy economics.

Brian Efird joined KAPSARC in 2013, where he is a senior research fellow and the program director for Human Geography of Energy. He has a PhD and is responsible for managing a research program that comprises a multi-disciplinary, multi-national team of researchers who produce innovative, policy-relevant research on energy issues that contribute to societal welfare. Brian's research teams focus on a variety of topics, including China, India, the GCC, East Africa and local content.

Steven Griffiths is the vice president for research and a professor of practice at Masdar Institute of Science and Technology. Steven has overall responsibility for research, including large-scale, collaborative research programs and centers, research development, sponsored programs, technology transfer and research laboratories. Additionally, he has an active role in multiple industry, research and innovation bodies outside of Masdar Institute, including the Middle East Solar Industry Association Board of Directors and the Zayed Future Energy Prize Selection Committee. He holds a PhD in Chemical Engineering from Massachusetts Institute of Technology (MIT) and an MBA from the MIT Sloan School of Management.

Zhu Hanxiong is a research associate at Fudan University Energy Research Center. He has focused his research on energy policy of China, especially on Chinese coal supply chain and coal related $\mathrm{CO} 2$ emission accounting. As a key researcher, he participated in many national and regional level research projects on climate change and adaptation policy in China, national coal and regional energy planning.

Duc Huynh works in the Strategic Planning Department at Saudi Aramco. He was previously an oil and gas consultant based in Malaysia and Washington DC. He has a BA in East Asian Studies from the University of California, Los Angeles and a Masters in Economics from the University of California, San Diego.

Pan Kexi is a professor and vice director of Fudan University Energy Research Center. He has been committed to coal industry policy and technology for more than 30 years, especially with regard to the accounting and analysis of basic coal data for China. He has also led much national and provincial energy strategy planning and policy research.

Sameh El Khatib is an assistant professor in engineering systems management at Masdar Institute of Science and Technology. He received a bachelor's and a master's degree in electrical engineering from McGill University, Canada, in 2002 and 2005, respectively. He received his PhD from McGill University in 2011, where his research interests included power system economics, electricity market restructuring and planning, greenhouse gas regulation, as well as decisionmaking in the energy sector, specifically in the context of oligopolistic electricity markets. Sameh has previously worked as a management consulting associate at Booz \& Co. Currently, his research group focuses on unconventional hydrocarbons, cyber/physical sustainability of power systems and on modeling of the energy-water-food nexus, amongst others.

Ahmed Kiani is a postdoctoral research fellow in engineering system management at Masdar Institute of Science and Technology. He received 
his bachelor's in electrical engineering at McGill University, Canada, in 2007. He earned his master's degree in nanotechnology from University College London, in 2008 and a PhD in Electrical \& Electronic Engineering from University of Cambridge in 2014. Ahmed has previously served as head of renewable energy consulting in UAE/Pakistan and has worked as an investment banker in London. Currently, he is working on unconventional hydrocarbons, cyber-security of physical systems and energywater-food nexus.

Leo Lester PhD, CFA, FRM, is a former KAPSARC research fellow who led the China and North East Asia research. He previously worked in strategy and portfolio development for an international oil company.

Toufic Mezher is a professor of engineering systems and management at Masdar Institute of Science and Technology. Before Joining Masdar Institute, he was a professor of engineering management at the American University of Beirut from 1992 to 2007. He has a bachelor's degree in civil engineering from the University of Florida, and a master's and a DSc degree in engineering management from George Washington University in 1988 and 1992, respectively.

Yugo Nakamura, CFA, is industrial intelligence Manager with Aramco Asia Japan. He has been in energy space for 25 years and executed a number of business and research projects. Prior to joining, he was heading Bloomberg New Energy Finance Tokyo. Yugo earned an M.I.P.P from the School of Advanced International Studies, The Johns Hopkins University.

Larry R. Pederson currently serves as research director for energy security at the Qatar Environment \& Energy Research Institute (QUEERI), Hamad
Bin Khalifa University, focusing on topics in photovoltaics, energy storage and grid integration. Prior to joining QEERI, Pederson held the position of laboratory fellow at Pacific Northwest National Laboratory in Richland, Washington USA, where he was employed from 1978-2009 and from 2012-14. While at PNNL, Pederson served as director of the Materials Science and Engineering Division and of the High Temperature Electrochemistry Center. Pederson received his PhD in Physical and Surface Chemistry from the University of Wisconsin-Milwaukee.

Rémi Piet is assistant professor of international affairs and political economy at Qatar University where he coordinates research initiatives on energy, economics and sustainable development for the Gulf Studies Center. Remi Piet holds a PhD from the University of Miami and a MBA and an MA in International Relations from Laval University together with an MSc in International Economics from Université Paris La Sorbonne. He has authored more than a dozen scholarly articles and book chapters and wrote or coedited several books. Remi Piet has worked for several international organizations in Europe, the Middle East and the Americas such as the United Nations Environmental Programme and is a regular contributor for AI Jazeera, BBC, France 24, El Tiempo de Bogota and Al Arabiya.

Kuo Po-Yao is currently the section manager of the Energy Technology Development Center at the CTCI Foundation, Taiwan. Before working at the CTCI Foundation, he was an assistant research fellow of the Second Research Division, ChungHua Institution for Economic Research. Dr. Kuo's research interests include energy policies, energy trends, energy security, policies and technology assessment for energy saving and greenhouse gas emission reduction, electricity generation and emissions, vehicle energy use and emissions, and vehicle life-cycle analysis. 
Ji Qiang is an associate professor at the Center for Energy \& Environmental Policy Research, Institute of Policy and Management, Chinese Academy of Sciences. His research fields include energy security strategy management, energy economics and international energy trade. Ji has carried out and been involved in over 10 research projects, and has published over 30 papers in peer reviewed journals.

Yazeed Al-Rashed is a former senior research analyst at KAPSARC. Yazeed co-developed the KAPSARC GOTM. He has previously published work on energy efficiency in the OPEC Energy Review. He holds an SB in Chemical Engineering from the Massachusetts Institute of Technology and an MS in Energy Systems from Columbia University.

Jheng Ruei-he is an analyst at the Third Research Division, CIER, Taiwan. His research interests include energy economics, environmental economics, economic modeling, industrial economics and productivity analysis.

Antonio P. Sanfilippo is research director for measurement science and analytics in the Qatar Environment and Energy Research Institute, Hamad Bin Khalifa University. His current research focus is on solar resources and smart grid integration. From 2003 to 2014, Dr. Sanfilippo was chief scientist at the Pacific Northwest National Laboratory, in the U.S., where he directed a four-year research program on predictive analytics and led research projects funded by the Department of Homeland Security, the National Institutes of Health, and the National Science Foundation. Dr. Sanfilippo has MA and MPhil degrees in anthropological linguistics from Columbia University in the U.S., and a PhD in Cognitive Science from University of Edinburgh in the UK.
Sang Yoon Shin is an associate research fellow at the Korea Energy Economics Institute. His recent research includes "National Network through International Energy Organizations," "Oil Emergency Response Policy of Major Importing Countries and Implications," and "Cooperative Network of Oil Companies in East Asia," He is geographically interested in the Middle East and Central Asia. He received his PhD from the Katz Graduate School of Business, University of Pittsburgh.

Sammy Six is a research associate at KAPSARC covering oil and gas markets. Before joining KAPSARC he worked as a researcher with a leading think tank in the Netherlands. Sammy holds master's degrees in international politics and american studies from Ghent University and Antwerp University in Belgium, respectively.

Li Taoya, is a director in the International Division of the State Information Center. She graduated from the University of International Business and Economics of China with a master's degree in arts. Her research focus is international trade, public policy and urban planning. $\mathrm{Li}$ is also a coordinator and one of the authors in research projects with the World Bank and OECD on innovation and investment climate.

Li Tian-Yi is currently a junior student in the School of Economics, Renmin University of China. She is studying for dual degrees in economics and mathematics. She has participated in several international academic exchange seminars, including one in Doshisha University in Japan. Li also actively participates in academic competitions and has achieved many awards, including innovation and entrepreneurship practice of college students, mathematical modeling contest, undergraduate academic forum, and the national energy Internet challenge match. 
Zhang Tingting is a researcher on Chinese energy security at the International Energy Research Center (IERC). Her research interests focus on the life cycle assessment of energy system, as well as Chinese energy diplomacy. She has a PhD in Mechanical Engineering from Shanghai Jiao Tong University.

Omar Al-Ubaydli is the program director for international and geo-political studies at the Bahrain Center for Strategic, International and Energy Studies (DERASAT), an affiliated associate professor of economics at George Mason University, and an affiliated senior research fellow at the Mercatus Center. Omar previously served as a member of the Commonwealth of Virginia's Joint Advisory Board of Economists and a visiting professor of economics at the University of Chicago. He earned his BA in Economics from the University of Cambridge and his MA and PhD in Economics from the University of Chicago.

\section{Kenneth White is a former senior research} analyst at KAPSARC working on a variety of projects including consumer adoption of alternative energy and energy trade relations between Gulf Cooperation Council countries and North East Asia. Leveraging his background in quantitative and qualitative analysis, his research centers around applying data and statistics to generate actionable policy insights in fields as diverse as consumer behavior and geopolitics. He holds a Master in Public Policy and a Bachelor of Arts in Economics, both from Stanford University.

Steven Wright is an associate professor of international relations and gulf studies at Qatar University. His areas of research focus on the comparative politics and international relations of the Persian Gulf states, energy security and U.S. foreign policy toward the Middle East. Steven completed his education in the United Kingdom, graduating from the University of London and also Durham University where he completed his doctorate. He has held research fellowships at the London School of Economics, Exeter University and at the University of Durham. He was also elected a Fellow of the Royal Asiatic Society of the United Kingdom.

Zhao Xiaowei is an associate research fellow at the State Information Center of China and graduated from the Renmin University of China with a doctorate degree in economics. He has published more than 10 papers in the core journals like Finance and Trade Economics, Journal of International Trade, etc. Zhao is the author of Local Environmental Regulations and Regional 'Economic Growth: Theory, Proof and Policy, and Research on Industrial Economy Under the Energy Binding in the Resource-rich Regions: Xinjiang as An Example'.

Yukari Niwa Yamashita, is a board member and director of The Institute of Energy Economics, Japan, responsible for quantitative and qualitative analyses on energy policy issues. In the aftermath of the tsunami and nuclear incident in 2011, her team's recommendations influenced electricity saving campaigns and continue to contribute to the debate regarding a national energy mix for Japan. Yukari is responsible for an annual world energy and emissions outlook to assess the implications of technologies. She has been serving as a member of various government councils and committees in the fields of energy and science \& technologies. She leads international and regional energy cooperation programs through IEA, APEC, ERIA and IPEEC. She is currently a council member of the International Association for Energy Economics and the Clean Energy Education \& Empowerment Ambassador of Japan.

Vitaly Yermakov is an expert on Russian oil and natural gas markets with 20 years of industry experience. In 2008-15 he was research director 
with CERA and IHS Energy, focusing on Russia's oil and natural gas markets, analysis of Russia's investment climate, the tax and regulatory environment, and economic modeling. Vitaly is the author of over 50 CERA and IHS Energy strategic reports. He also led numerous consulting projects for the CERA and IHS Energy clients. He holds a master's degree from Duke University and a PhD from Samara State University.

Fan Ying is the dean of the School of Economics and Management at Beihang University. She attended Cornell University in the U.S. as a visiting scholar from 2004 to 2005 . Her research and teaching fields include energy-environmenteconomy system modelling, energy finance, climate change, energy and environmental policy. Fan is currently the vice president of the International Association for Energy Economics. She has carried out over 60 research projects and published over 200 papers in peer reviewed journals.

Liu Yu-lin is a research assistant at the Taiwan WTO and RTA Center, CIER. His research interests focus on strategic interactions between China and its peripheral states, the nexus of security and economy in Asia-Pacific, strategic studies and alliance politics.

Chen Zhan-Ming is an associate professor in the Department of Energy Economics, Renmin University of China. He also serves as a researcher in the National Academy of Development and Strategy, also at Renmin University of China. He received his doctorate from College of Engineering, Peking University in 2011 and BS/BEc from Department of Mechanics and Engineering Science/ China Center for Economics Research, Peking University, in 2006. Chen's current research focuses on energy economics and policy. He has published over 40 peer-reviewed papers with an $\mathrm{H}$-index of 18 and overall citations above 700 .

Chang Zheng is a post-doctoral researcher at the Fudan Development Institute. Her research areas are energy system modeling and policy simulation, GHG inventory compiling, carbon emission mitigation and public policy making. 


\section{Notes}

.

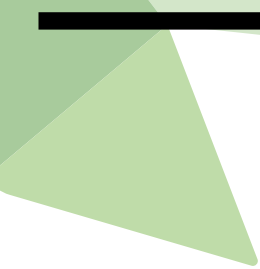


Notes

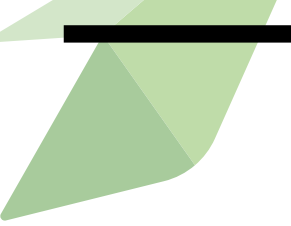


INAPSARC

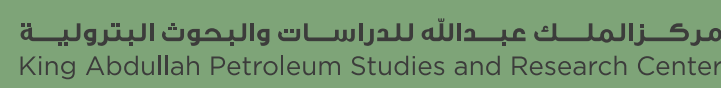

www.kapsarc.org 